\title{
Vacuum superplastic deformation behavior of a near-alpha titanium alloy TA32
}

\author{
Chao Cheng ${ }^{1,2}$, Weitang Zhang ${ }^{3}$, Zhiyong Chen ${ }^{1,2}$, Liang Jin $^{3}$ and Qingjiang Wang ${ }^{1,2}$ \\ ${ }^{1}$ Division of Titanium alloys, Institute of Metal Research, Chinese Academy of Sciences, 72 Wenhua Road, Shenyang 110016, China \\ ${ }^{2}$ School of Materials Science and Engineering, University of Science and Technology of China, Hefei 230026, China \\ ${ }^{3}$ Beijing Electro-Mechanical Engineering Institute, Beijing 100074, China
}

Corresponding author: Zhiyong Chen, E-mail: zhiyongchen@imr.ac.cn

\begin{abstract}
$\underline{\text { Abstract }}$
TA32 is a heat-resistant titanium alloy developed for superplastic forming in fabrication of near-space supersonic aerocraft. Clarification of superplastic deformation behavior is important to the optimization of forming parameters. Superplastic tensile test was conducted in vacuum to eliminate the effect of surface oxidation on experimental data, the test temperature and strain rate varied from $900^{\circ} \mathrm{C}$ to $960^{\circ} \mathrm{C}$ and $5.32 \times 10^{-4}$ to $2.08 \times 10^{-2} \mathrm{~s}^{-1}$, respectively. It was observed that the size of equiaxed $\alpha$ grains exhibited a trend of coarsening with the increase of temperature and decrease of strain rate. Textures of deformed specimens exhibited random distribution with a decreased texture intensity compared with the as-received materials. The superplastic deformation mechanism of TA32 alloy was dominated by grain boundary sliding, which is accommodated by grain rotation and dynamic recrystallization.
\end{abstract}

\section{Introduction}

As the excellent combination properties such as high ratio of strength to weight, superior high temperature resistance, remarkable corrosion resistance and so on, titanium and its alloys have been widely applied in aviation, aerospace, marine and biomedical fields [1]. However, due to the hexagonal close-packed (HCP) structure of $\alpha$ phase with limited number of active slip systems, titanium alloys have a poor plastic deformation capacity at low temperature. Therefore, to broaden the application fields of titanium alloys, especially in the aerospace industry, extensive researches on superplastic forming (SPF) of titanium alloys have been carried out [2-5]. The advantages of SPF are as follows: saving materials and improving product quality, increasing strength and reducing final weight of the components, improving the life of die and achieving very complex shape parts [6]. As a result, it is urgently necessary that SPF is applied on titanium alloys. However, according to previous studies [7-9], the SPF experiments are always conducted in atmospheric environment. Although anti-oxidation coating is applied on the surface of test samples in most experiments, the inevitable oxidation will create some degree of distortion on the experimental data.

TA32 titanium alloy is a near $\alpha$ high temperature titanium alloy designed by Institute of Metal Research, Chinese Academy of Sciences. The alloy has excellent properties in tensile strength, ductility and creep property at $550^{\circ} \mathrm{C}$, also, it possesses good short-term high temperature performance at $600^{\circ} \mathrm{C}-650^{\circ} \mathrm{C}$. In recent years, sheets of TA 32 alloy is applied massively in high temperature structures of near-space supersonic aerocraft. SPF is a key process in the fabrication of thin-walled production such as wing panels in high speed plane. Thus, the purpose of this paper is aimed at fully understanding of the vacuum superplastic deformation mechanism of TA32 sheet.

\section{$\underline{\text { Experimental Procedure }}$}

The as-received material used in present study was hot rolled and annealed TA32 sheet (2mm in thickness) with composition (in wt.\%) of (5.0 5.5) Al, (3.0 3.5) Sn, (2.5 3.5) $\mathrm{Zr},(0.7 \sim 1.2) \mathrm{Mo},(0.2 \sim 0.7) \mathrm{Nb},(0.2 \sim 0.7) \mathrm{Ta},(0.2 \sim 0.4) \mathrm{Si}$, balance Ti. The $\beta$ transus temperature is about $995{ }^{\circ} \mathrm{C}$ as determined with metallographic method. Superplastic deformation tests were performed along the longitudinal direction in the temperature of $900-960^{\circ} \mathrm{C}$ with $20^{\circ} \mathrm{C}$ intervals using the initial strain rates of $2.08 \times 10^{-2}, 3.33 \times 10^{-3}$ and $5.32 \times 10^{-4} \mathrm{~s}^{-1}$. The superplastic tensile tests were performed on MTS CMT-4304 microcomputer controlled electronic universal testing machine equipped with a vacuum furnace (vacuum degree, $10^{-4} \mathrm{~Pa}$ ). The average grain sizes (for primary $\alpha$ phase) were determined by the linear intercept method. The microstructures of the as-received materials and after SPF deformation were observed using HITACHI S-3400N scanning electron microscope (SEM). The texture characterizations were conducted by using Electron back scattering diffraction (EBSD) technique.

\section{$\underline{\text { Results and Discussions }}$}

(C) The Authors, published by EDP Sciences. This is an open access article distributed under the terms of the Creative Commons Attribution License 4.0 (http://creativecommons.org/licenses/by/4.0/). 
Figure 1 shows SEM images taken from the longitudinal direction of the as-received material. A equiaxed structure composed of primary $\alpha$ phases (hexagonal close-packed, hcp, dark in Fig. 1) and thin $\beta$ phases (body-centered cubic, bcc, bright in Fig. 1) was observed and the size of average primary equiaxed $\alpha$ phase was measured to be approximately $2.1 \mu \mathrm{m}$. Figure 2 shows the textures of as-received material obtained by EBSD technique. Nearly consistent crystal orientation was observed in Figure 2 (a). It can also be observed from the pole figure (Figure 2 (b)) that the c-axis directions in $\alpha$ phase texture are perpendicular to the plate planar. This type of texture was defined as basal texture that is a typical texture in titanium alloys [10]. However, the $\beta$ phase presented a random distribution of crystal orientation compared to the texture component of $\alpha$ phase. Figure 2 (c) shows the distribution of grain boundary misorientation angle of the as-received material. The fraction of high angle grain boundaries $\left(\mathrm{HAGBs},>15^{\circ}\right)$ was calculated to be $18.1 \%$ while the low angle grain boundaries (LAGBs, $<15^{\circ}$ ) took up the main portion with $81.9 \%$. The average misorientation angle was estimated to be $11.6^{\circ}$.

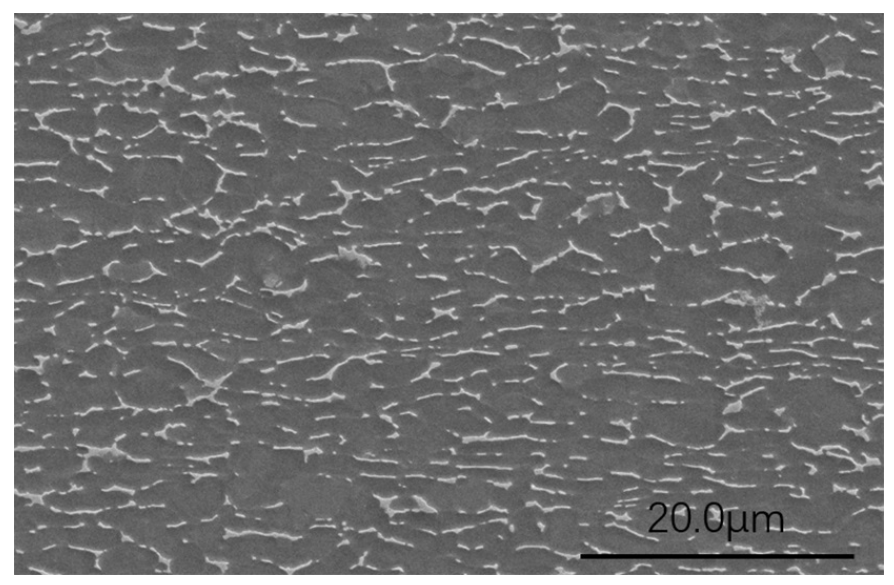

Figure 1. Microstructure of the as-received material. 


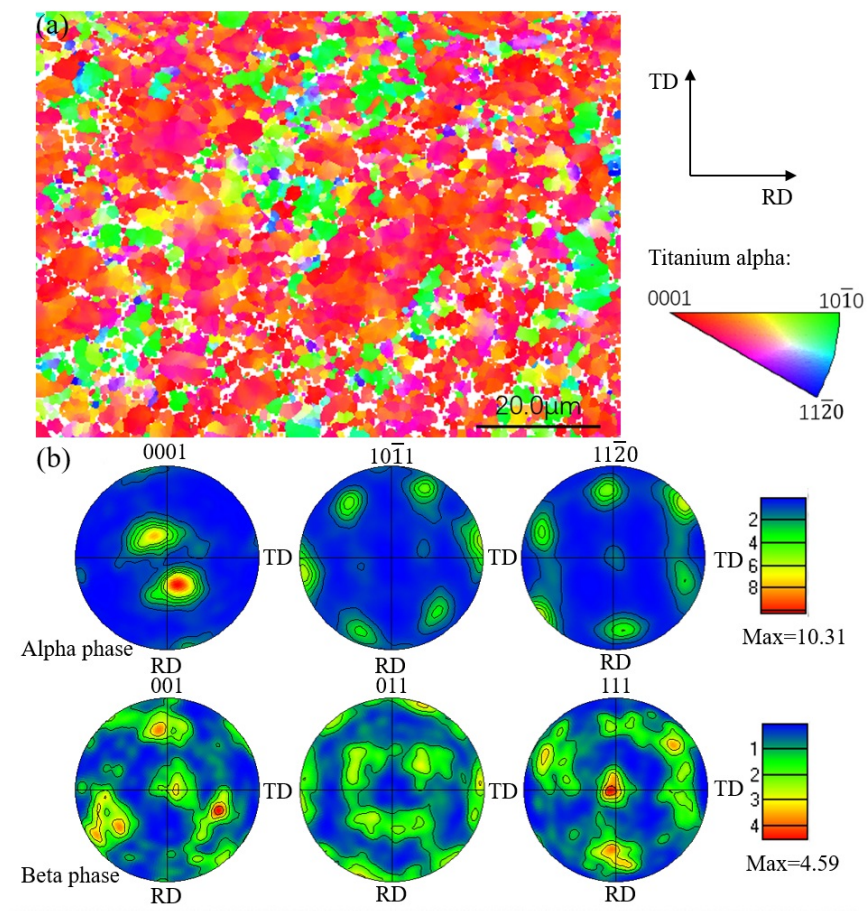

(c)

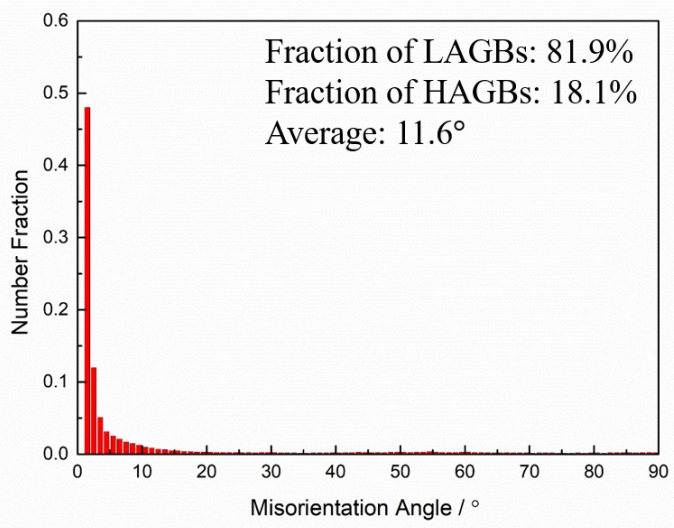

Figure 2. Texture of the as-received material: (a) inverse pole figure, (b) pole figure, (c) misorientation angle distribution.

Superplastic deformation behavior

The true stress versus true strain curves of TA32 alloy after superplastic deformation test are shown in Figure 3 . It can be clearly observed that strain hardening occurs at the beginning of deformation, which could be ascribed to high dislocation multiplication ratio under all deformation conditions [8]. In addition, it can be found that the peak flow stress decreases with increasing tensile temperature or decreasing strain rate. The flow softening occurs when the stress reaches a peak value, but exhibits different characteristics when the tensile temperature and rate changes. Flow stress is found to decrease more quickly at $900{ }^{\circ} \mathrm{C}$ (Figure $3(\mathrm{a})$ ) and $2.08 \times 10^{-3} \mathrm{~s}^{-1}$ (Figure $3(\mathrm{~b})$ ) but decrease relatively gently at other tensile temperatures and rates, which indicates a competitive difference between the working hardening and softening mechanism under different deformation conditions. A slight increase of stress at the end of stress-strain curve can be observed at temperature of $920{ }^{\circ} \mathrm{C}$ and $940{ }^{\circ} \mathrm{C}$ with tensile rate of $3.33 \times 10^{-}$ 3 and $5.32 \times 10^{-4} \mathrm{~s}^{-1}$, which may be ascribed to working hardening associated with the grain growth.

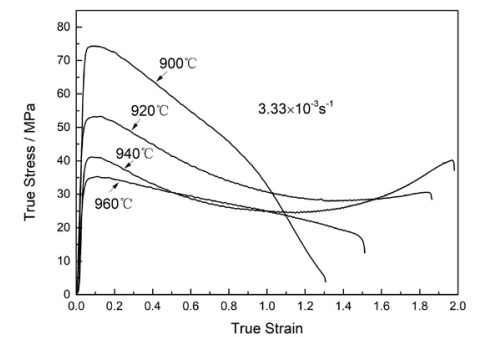

(b)

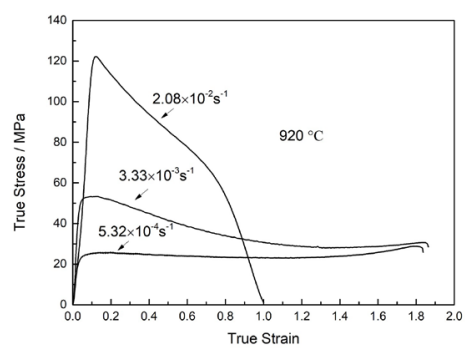


Table 1 shows tensile elongation values at different deformation conditions. It is shown that TA32 sheet exhibits good superplasticity with a maximum elongation of $632 \%$ at $940^{\circ} \mathrm{C}$ with an initial strain rate of $3.33 \times 10^{-3} \mathrm{~s}^{-1}$. It is noted that high temperature and low strain rate would be good for improvement of superplasticity. The superplasticity of the sheet exhibits an obvious decrease when strain rate increase from $10^{-4} \mathrm{~s}^{-1}$ to $10^{-2} \mathrm{~s}^{-1}$ at the same temperature, which may be ascribed to the uncoordinated effect of the grain boundary sliding, diffusion creep and dislocation slip. It is thought that high strain rate would result in rapidly increased dislocations which is not conducive to uniform deformation [11].

Table 1 Percent elongation-to-failure values at different deformation conditions

\begin{tabular}{|c|c|c|c|c|}
\hline & $900^{\circ} \mathrm{C}$ & $920^{\circ} \mathrm{C}$ & $940^{\circ} \mathrm{C}$ & $960^{\circ} \mathrm{C}$ \\
\hline $5.32 \times 10^{-4} \mathrm{~s}^{-1}$ & $366 \%$ & $541 \%$ & $470 \%$ & $610 \%$ \\
\hline $3.33 \times 10^{-3} \mathrm{~s}^{-1}$ & $277 \%$ & $553 \%$ & $632 \%$ & $364 \%$ \\
\hline $2.08 \times 10^{-2} \mathrm{~s}^{-1}$ & $204 \%$ & $176 \%$ & $166 \%$ & $137 \%$ \\
\hline
\end{tabular}

Microstructure after superplastic deformation

Figure 4 shows the microstructures at gauge regions of the samples after superplastic deformation at an initial strain rate of $3.33 \times 10^{-3} \mathrm{~s}^{-1}$. It is shown that the primary $\alpha$ grains is coarsened and fully globularized after deformation, which is mainly caused by dynamic recrystallized promoted by the accumulated distortion energy during superplastic deformation $[9,12]$. Furthermore, the size of primary $\alpha$ grains increased with increase of tensile temperature. It is thought that the diffusion creep and grain boundary sliding would be enhanced through improvement of dislocation activity with increase of temperature [13], and the equiaxed $\alpha$ grains are thought to be more beneficial to grain boundary sliding during high temperature tensile test. Figure 5 exhibits the influence of initial strain rates on microstructure at $940^{\circ} \mathrm{C}$. It can be observed that the primary $\alpha$ grains are relatively fine and uniform at high strain rate, which may be ascribed to the promotion effect of the dynamic recrystallization at high initial strain rate. However, when the strain rate becomes lower, the heating duration becomes longer. And the agglomeration of dynamic recrystallization grains can easily occur during high temperature deformation, which would lead to the merging and growth of alpha phase grains.
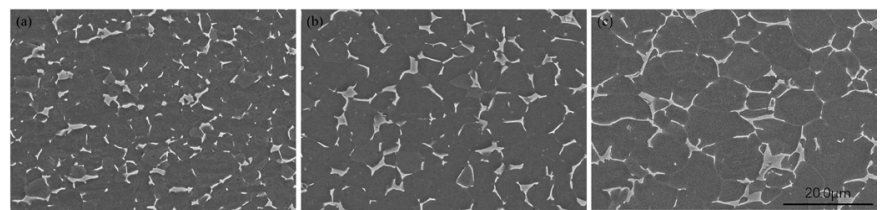

Figure 4 Micrographs of TA32 alloy after superplastic deformation at various deformation temperatures $\left(\dot{\varepsilon}=3.33 \times 10^{-3} \mathrm{~s}^{-1}\right)$ at the gauge region: (a) $900^{\circ} \mathrm{C},\left(\right.$ b) $920^{\circ} \mathrm{C}$ and $(\mathrm{C}) 960^{\circ} \mathrm{C}$.
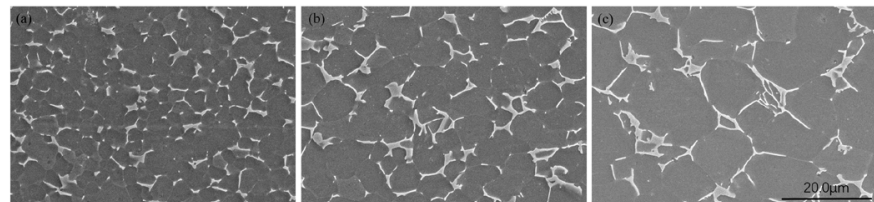

Figure 5 Micrographs of TA32 alloy after superplastic deformation at various initial strain rates $\left(\mathrm{T}=940^{\circ} \mathrm{C}\right)$ at the gauge region: (a) $2.08 \times 10^{-2} \mathrm{~s}^{-1},(\mathrm{~b}) 3.33 \times 10^{-3} \mathrm{~s}^{-1}$ and $(\mathrm{c}) 5.32 \times 10^{-4} \mathrm{~s}^{-1}$.

Figure 6 shows the change of primary $\alpha$ grains at the gauge region under different deformation conditions. It is shown that the grain size increases with the decrease of initial strain rate and increase of deformation temperature. Also, the grains grow rate has a similar trend with the deformation conditions. The maximum primary $\alpha$ grain size can reach to $11.5 \mu \mathrm{m}$ after deformed at $960^{\circ} \mathrm{C}$ with an initial strain rate $5.32 \times 10^{-4} \mathrm{~s}^{-1}$. It is mainly resulted from enhancement of dynamic recrystallization and grain growth of TA32 alloy under high temperature and low strain rate. 


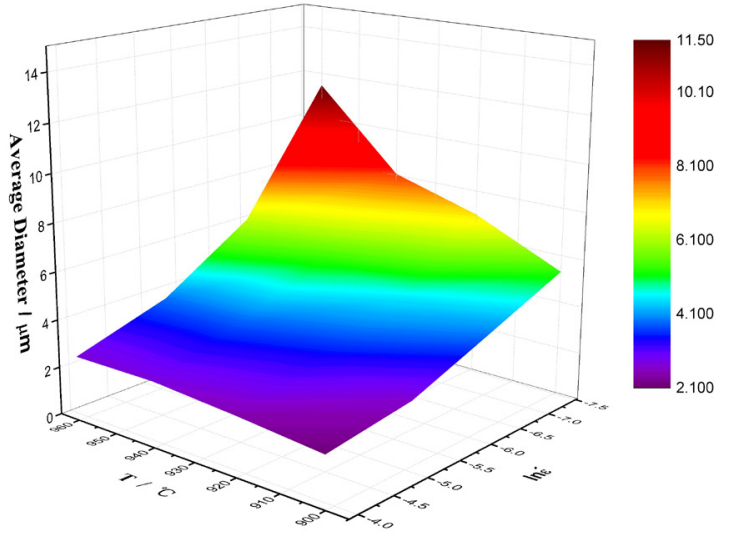

Figure 6. Effect of deformation condition on the size of primary $\alpha$ grains.

To further investigate the evolution of the microstructural characteristics during the superplastic deformation, EBSD was employed at different location of the deformed sample at $940^{\circ} \mathrm{C}$ with an initial strain rate $5.32 \times 10^{-4} \mathrm{~s}^{-1}$, as shown in Figure 7 . It can be clearly seen from Figure 7 (a) that the surface of the deformed sample still shows a good metallic luster after the superplastic deformation, which convincingly demonstrate that the vacuum environment is good for oxidation protection during high temperature deformation. The $\alpha$ grains at the grip region is observed to be coarsened but the texture type and intensity exhibit nearly no changes (Figure 7 (b) and (d)). This is primarily because this region is only subjected to thermal cycling and no deformation during tensile test. Randomized orientations of $\alpha$ grains with a maximum texture intensity of 6.43 can be observed at the gauge region (Figure 7 (c) and (e)), which is due to grain rotation during tensile deformation [14-16]. This result also supports that grain boundary sliding is the main mechanism of superplastic deformation [5]. The misorientation angle distribution and average misorientation angle at the gauge regions were calculated and analyzed, as shown in Figure 8. It can be observed that there is a dramatical shift that grain misorientation angles change from LAGBs toward HAGBs compared to the initial misorientation angle distribution (Figure 1 (c)). The average grain misorientation angle was calculated to $41.1^{\circ}$, which is much higher than that of as-received material with $11.6^{\circ}$. Generally, a large fraction of LAGBs represents the presence of deformed microstructure, while the large fraction of HAGBs refers to the recrystallized microstructure. Therefore, the increases of HAGBs and the average grain misorientation angle at the gauge region after superplastic deformation can be attributed to dynamic recrystallization and its consequent grain boundary sliding. Z.G. Liu [9] also reported that the nucleation and growth of dynamically recrystallized grains can accelerate annihilation of dislocations in the grains during dynamic recrystallization, and consequently result in a lower fraction of LAGBs. Based on the discussion above, it is concluded that the superplastic deformation mechanism of TA32 sheet is grain boundary sliding accommodated by dynamic recrystallization and grain rotation.

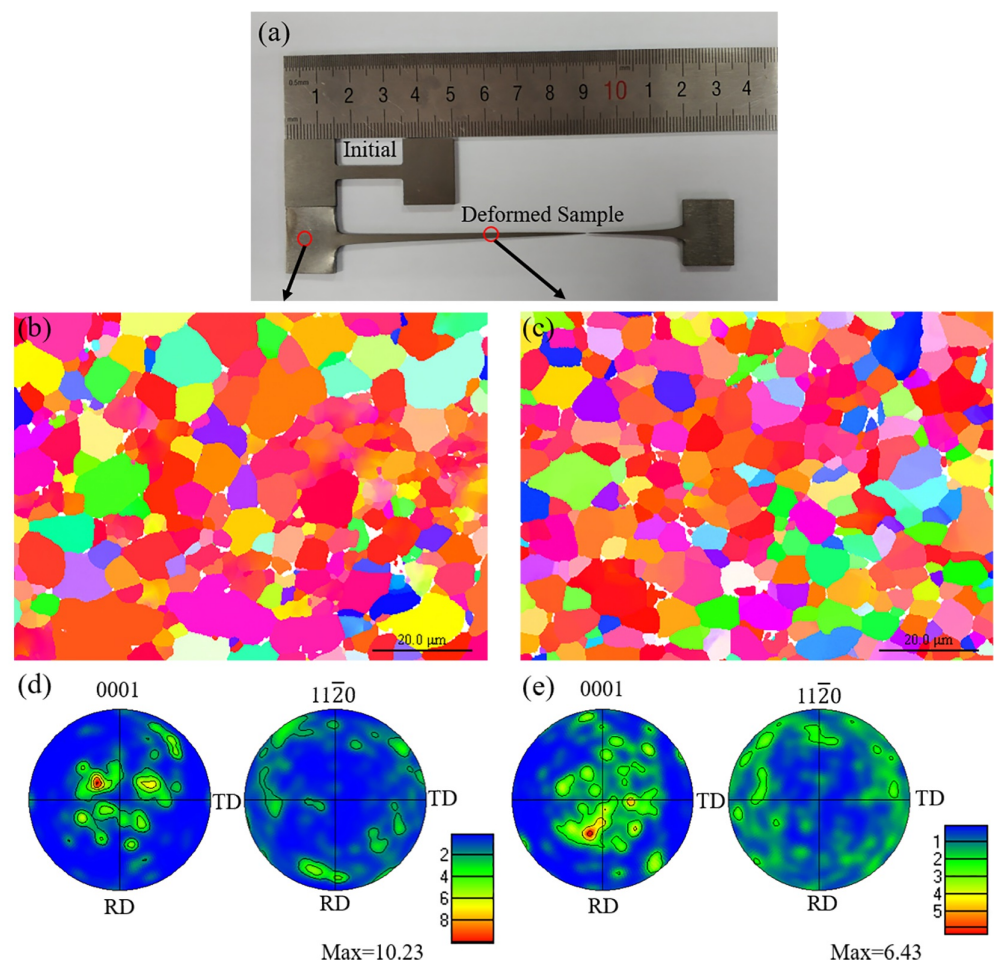

Figure 7. Macro morphology and texture features of the deformed material $\left(\mathrm{T}=940^{\circ} \mathrm{C}, \dot{\varepsilon}=3.33 \times 10^{-3} \mathrm{~s}^{-1}\right)$ : (a) macro morphology, (b) inverse pole figure and (d) pole figure at the grip region, (c) inverse pole figure and (e) pole figure at the gauge region. 


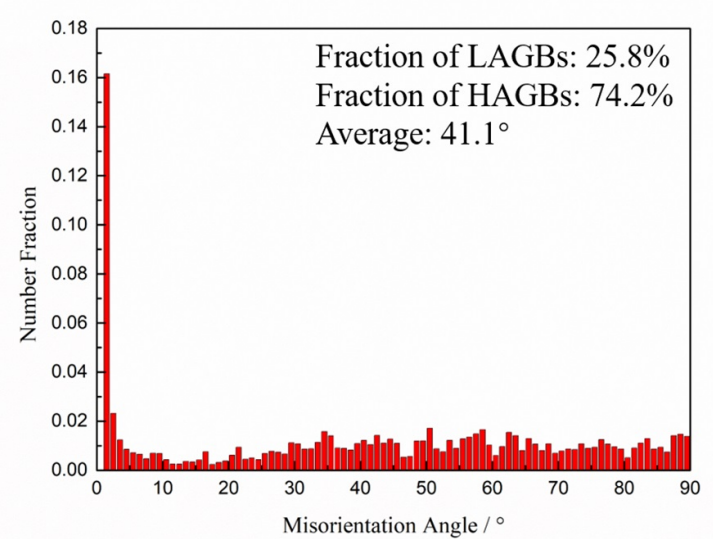

Figure 8. Misorientation angle distribution of the deformed material $\left(\mathrm{T}=940^{\circ} \mathrm{C}, \dot{\varepsilon}=3.33 \times 10^{-3} \mathrm{~s}^{-1}\right)$ at the gauge region.

\section{Summary}

The superplastic deformation properties of a near $\alpha$ titanium alloy TA32 was investigated in vacuum environment and the results could be summarized as follows:

1. Vacuum environment can effectively prevent the material from being oxidized.

2. The primary $\alpha$ grains are spherized and coarsened during the superplastic deformation, and the grain size exhibits a trend of increase with the decrease of initial strain rate and increase of temperature.

3. The crystal orientation is randomized with the decrease of texture intensity and the fraction of HAGBs increase after superplastic deformation.

4. The superplastic deformation mechanism is identified as the primary grain boundary sliding accommodated dynamic recrystallization and grain rotation.

\section{$\underline{\text { References }}$}

[1] Lutjering G, Williams J C. Titanium. Germany: Springer, 2003.

[2]D.S. McDARMAID, et al., Journal of Materials Science, 20 (1985), 1976.

[3] J.S. Kim, et al., Materials Science and Engineering: A 263 (1999), 272.

[4] P. Lin, et al., Materials Science \& Engineering: A, 556 (2012), 617.

[5] E. Alabort, et al., Acta Materialia, 95 (2015), 428.

[6] M.J. Tan, et al.,Journal of Materials Processing Technology, 192-193 (2007), 434.

[7] X.M. Zhang, et al., Materials Science \& Engineering: A, 560 (2013), 700.

[8] Q.J. Sun, et al., Materials Science \& Engineering: A, 606 (2014), 401.

[9] Z.G. Liu, et al., Materials Science \& Engineering: A, 680 (2017), 259.

[10] S. F. Frederick, et al., Metallurgical Transactions: B, 6B (1975), 601.

[11] B. Xi, et al., Chinese Journal of Rare Metals, 38(2) (2014), 328.

[12] Z.C. Sun, et al., Materials Characterization, 90 (2014), 71.

[13] L.Y. Zeng, et al., Rare Materials and Engineering, 34(12) (2005), 1940.

[14]M. T. Pérez-Prado, et al., Acta Materialia, 49 (2001), 2259. 
[15]R. Panicker, et al., Acta Materialia, 57 (2009), 3683.

[16] H. Watanabe, et al., Materials Science \& Engineering: A 558 (2012), 656. 